\title{
MULTICOMPONENT AND DOMINO REACTIONS IN THE SYNTHESIS OF HETEROCYCLIC COMPOUNDS
}

Dear colleagues, the latest thematic issue of "Chemistry of Heterocyclic Compounds" journal, devoted to the application of multicomponent and domino reactions in the synthesis of heterocycles, is brought to your attention.

Progress in the organic synthesis methods development usually involves perfection of the individual stages and the general methodology, which makes it possible to reduce their number. In recent decades impressive results have been obtained in this area. However, any multistage reaction has fundamental limitations, which prevent it from being fully effective. Most of all, it entails a reduction of yield at each stage of the process arising from the need to isolate and purify the intermediates. A fundamentally new approach is introduced in syntheses based on the use of domino reactions as a whole and their subclass, multicomponent reactions, in particular. Multicomponent reactions imply processes that occur when three or more starting compounds are mixed directly,

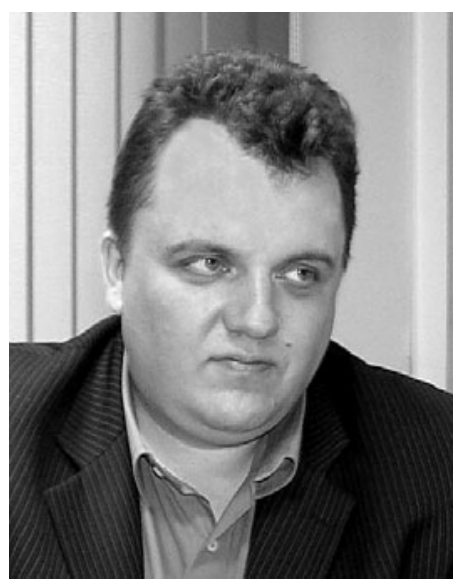
where the structure of the product must contain fragments of all the starting compounds. The term "multicomponent reactions" was introduced by I. Ugi at the beginning of the sixties of last century. To be fair, however, it should be pointed out that their history covers more than a century and a half and many reactions of this type have firmly entered the arsenal of synthetic chemists including the well-known Biginelli and Passerini reactions.

This special issue presents both analytical reviews on the use of various multicomponent and domino reactions in the synthesis of heterocyclic compounds and experimental papers on this urgent and rapidly developing subject. It is to be hoped that readers of "Chemistry of Heterocyclic Compounds" will find for themselves much new and interesting information that they can use in their daily scientific work.

On behalf of the editorial board and myself personally I would like to express sincere gratitude to all the authors for the material they have provided. We hope that also in the future you will choose "Chemistry of Heterocyclic Compounds" journal for publication of your new scientific results.

\author{
Professor, Doctor of Chemical Sciences L. G. Voskressensky
} Peoples' Friendship University of Russia

Translated from Khimiya Geterotsiklicheskikh Soedinenii, No. 4, pp. 575, April, 2012. 